\title{
Signaling from the cytoplasm to the nucleus in striatal medium-sized spiny neurons
}

\author{
Miriam Matamales ${ }^{1,2,3}$ and Jean-Antoine Girault ${ }^{1,2,3}$ * \\ 1 UMR-S 839, Inserm, Paris, France \\ 2 Université Pierre et Marie Curie, Paris, France \\ ${ }^{3}$ Institut du Fer à Moulin, Paris, France
}

\section{Edited by:}

Emmanuel Valjent, Université

Montpellier 1 \& 2, France

Reviewed by:

Eric J. Nestler, Mount Sinai School of

Medicine, USA

Michael R. Kreutz, Leibniz-Institute for

Neurobiology, Germany

*Correspondence:

Jean-Antoine Girault, Institut du Fer à Moulin, Inserm UPMC UMR-S 839,

17 rue du Fer à Moulin, 75005 Paris,

France.

e-mail: jean-antoine.girault@inserm.fr

${ }^{t}$ Present address:

Miriam Matamales, Alzheimer's \&

Parkinson's Disease Laboratory,

Brain \& Mind Research Institute,

University of Sydney, 100 Mallett St,

Camperdown, NSW 2050, Australia
Striatal medium-sized spiny neurons (MSNs) receive massive glutamate inputs from the cerebral cortex and thalamus and are a major target of dopamine projections. Interaction between glutamate and dopamine signaling is crucial for the control of movement and reward-driven learning, and its alterations are implicated in several neuropsychiatric disorders including Parkinson's disease and drug addiction. Long-lasting forms of synaptic plasticity are thought to depend on transcription of gene products that alter the structure and/or function of neurons. Although multiple signal transduction pathways regulate transcription, little is known about signal transmission between the cytoplasm and the nucleus of striatal neurons and its regulation. Here we review the current knowledge of the signaling cascades that target the nucleus of MSNs, most of which are activated by cAMP and/or $\mathrm{Ca}^{2+}$. We outline the mechanisms by which signals originating at the plasma membrane and amplified in the cytoplasm are relayed to the nucleus, through the regulation of several protein kinases and phosphatases and transport through the nuclear pore. We also summarize the identified mechanisms of transcription regulation and chromatin remodeling in MSNs that appear to be important for behavioral adaptations, and discuss their relationships with epigenetic regulation.

Keywords: medium-sized spiny neurons, dopamine, glutamate, protein phosphorylation, cytonuclear shuttling, transcription, chromatin remodeling, epigenetic regulation

\section{WHY IS CYTONUCLEAR SIGNALING IMPORTANT IN NEURONS?}

In interphasic eukaryotic cells the genetic material, the DNA, is segregated from the rest of the cell by the double membrane of the nuclear envelope which separates the nucleus from the cytoplasm. Communication between the two compartments is tightly regulated and essentially restricted to highly organized nuclear pores (Hoelz et al., 2011). The cytoplasm is the site of housekeeping functions common to all cell types, as well as highly specialized activities, such as those characteristic of synapses. Thus, the regulation of gene expression is under two opposite constraints. On the one hand the pattern of gene expression characteristic of the differentiated state of the cell must be very stable. On the other hand, fine tuning of gene expression is constantly required for the cell to adapt to its environment and respond to new demands.

In neurons gene transcription and protein synthesis have been known for many years to be necessary for the long-lasting changes that underlie learning and memory (Goelet et al., 1986; Black et al., 1987). The pattern of gene transcription depends on the dynamic interplay of numerous transcription factors, binding to promoter, enhancer, and silencer regions. It also depends on the organization of the chromatin, including covalent modification of nucleotides, such as cytidine methylation, and post-translational modifications of histones, which form the core of nucleosomes around which DNA is wrapped. These modifications control the accessibility of DNA and the recruitment of transcription factors and other proteins through their specialized targeting domains. The resulting chromatin remodeling may provide the basis for "epigenetic" control of long-lasting neuronal adaptations (see Levenson and Sweatt, 2005; Borrelli et al., 2008; Day and Sweatt, 2010; Riccio, 2010, for reviews). The use of the word epigenetic has been the source of debates however. As originally defined, and recently reasserted, "An epigenetic trait is a stably heritable phenotype resulting from changes in a chromosome without alterations in the DNA sequence" (Berger et al., 2009). According to this stringent definition neurons, like other post-mitotic cells, could not undergo new epigenetic alterations (except perhaps by erasing existing epigenetic marks...). The word is often used in a less strict sense to designate long-lasting chromatin covalent modifications, a trend that has raised some criticisms as it may have misleading implications in terms of underlying mechanisms (Ptashne, 2007). At any rate a wealth of recent findings summarized in this review underlines the importance of the regulation of covalent modifications of histones and DNA by cytonuclear signaling pathways in striatal neurons.

A striking feature of most chromatin modifications is that they are highly dynamic, implying efficient regulatory mechanisms and active control mechanisms if they are to be maintained for long periods of time (Henikoff, 2008). In addition, the chromatin is topographically organized due to a highly complex network of 
long range interactions, which are only starting to be deciphered in non-neuronal cells (Fraser and Bickmore, 2007). This higher level of chromatin organization is still largely a terra incognita in neurons. Interestingly, the patterns of heterochromatin staining, which result from the organization of the nuclear material, differ widely between neurons and other cell types and between different neuronal populations (Ramon y Cajal, 1899) but their significance and regulation have received little attention so far. In the striatum, this pattern allows to differentiate medium-sized spiny neurons (MSNs) from other cells (Matamales et al., 2009) and recent work suggests that the geometry and organization of the nucleus can undergo rapid and dramatic alterations in response to synaptic activity (Wittmann et al., 2009; Maze et al., 2011). Therefore deciphering the control of nuclear functions and organization in neurons represents a major challenge for understanding the neurobiology of learning and memory and brain plasticity.

An important issue to be addressed is how synaptic activity modifies gene transcription and chromatin remodeling. It has been proposed that information transmitted from synapses can alter nuclear function through at least two different pathways (see Deisseroth and Tsien, 2002; Adams and Dudek, 2005; Cohen and Greenberg, 2008; Jordan and Kreutz, 2009, for reviews and discussion): (i) a "synapse-to-nucleus" pathway in which proteins can move from activated synapses to the nucleus and control nuclear events such as transcription; (ii) a "soma-to-nucleus" pathway without direct transport of macromolecules from the synapses, but in which action potentials and second messengers such as $\mathrm{Ca}^{2+}$ or cAMP generated in the perikaryon control nuclear signaling. In the context of learning, it has been contended that the "soma-to-nucleus" model might be the most relevant mechanism because it is faster and may involve a cell-type specific threshold of activation, preventing the activation of other irrelevant genes (Adams and Dudek, 2005). However, it is likely that the two types of pathways act in combination over different time scales to achieve a precise tuning of nuclear function.

In this review we focus on MSNs, which are the most prevalent cell type of the striatum, comprising about $95 \%$ of striatal neurons in rodents (Tepper and Bolam, 2004). Since these neurons play an essential role in the circuits of the basal ganglia and are thought to undergo enduring adaptations important for procedural memory (Kreitzer, 2009), it is important to decipher the cytonuclear signaling pathways that trigger long-lasting changes in MSNs. Such changes are also likely to underlie some of the dysfunctions of the basal ganglia, in conditions such as drug addiction, L-DOPAinduced dyskinesia in Parkinson's disease, and, presumably, several other neuropsychiatric disorders.

\section{MAJOR SIGNALING PATHWAYS IN MSNs}

The striatum is the main entry station of the basal ganglia and MSNs are its sole output neurons. MSNs utilize GABA as their major neurotransmitter, making the striatum a large inhibitory structure (Yoshida and Precht, 1971). MSNs receive excitatory glutamatergic inputs from the cortex and the thalamus, which contact dendritic spines and are modulated by dopamine (DA) released from the terminals of midbrain DA neurons (Bennett and Wilson, 2000). They also receive various other types of afferences including inhibitory synapses originating from other MSNs and
GABAergic interneurons, cholinergic inputs from large cholinergic interneurons, and several others such as serotonine, and various neuropeptides. Most of the present knowledge of gene regulation in the striatum results however from the study of dopamine and glutamate signaling, for which we provide a brief overview.

\section{DOPAMINE RECEPTORS SIGNALING}

The actions of dopamine in the striatum are mediated mainly by the D1 and D2 types of DA receptors (D1R and D2R) that are coupled to different $G$ proteins having opposite effects on the production of cAMP (Kebabian and Calne, 1979). D2Rs have a high affinity for DA and are tonically activated by low basal concentrations of DA in the extracellular space, whereas D1Rs are thought to be stimulated following burst firing of DA neurons which is more efficient to release DA (Creese et al., 1983; Grace, 1991). $\mathrm{D} 1 \mathrm{Rs}$ are coupled to the striatal-enriched $\mathrm{G} \alpha_{\text {olf }}$ that stimulates adenylyl cyclase activity, thus increasing intracellular cAMP levels (Herve et al., 1993; Corvol et al., 2001; Figure 1). The principal target of cAMP is the cAMP-dependent protein kinase (PKA; Miyamoto et al., 1968) and D1R-induced PKA activation modulates multiple voltage- and ligand-gated ion channels, thereby modifying the effectiveness of synaptic inputs (Greengard et al., 1999; Nicola et al., 2000). In contrast to the phasic stimulation of D1Rs, D2Rs exert a tonic inhibitory effect on membrane potential and adenylyl cyclase, thereby opposing other receptors expressed in the same neurons such $\mathrm{A} 2 \mathrm{a}$ adenosine receptors. There is also a biphasic coupling of D2R with the Akt/GSK3 pathway, which includes an early activation (Brami-Cherrier et al., 2002) and a delayed inhibition linked to protein phosphatase 2A (PP2A) recruitment (Beaulieu et al., 2005). Although the Akt/GSK3 pathway is known to exert important effects on nuclear functions in other cell types (Hur and Zhou, 2010), little is known about such effects in the striatum. As initially proposed more than 20 years ago (Gerfen et al., 1990), D1Rs and D2Rs are remarkably segregated in striatonigral and striatopallidal neurons, respectively, with little overlap (see Valjent et al., 2009; Bertran-Gonzalez et al., 2010, for recent reviews). Interestingly, it has been shown that D1R-D2R heteromers can generate a specific $\mathrm{Gq} / \mathrm{Ca}^{2+}$-mediated signaling resulting in brain-derived neurotrophic factor (BDNF) induction (Hasbi et al., 2009). The physiological importance of this effect, which is expected to take place in the small proportion of MSNs coexpressing both receptors, remains to be fully evaluated. D3Rs are predominantly expressed in the ventral striatum (Diaz et al., 1995).

\section{THE ERK PATHWAY AND SYNERGISM BETWEEN D1R AND GLUTAMATE RECEPTORS}

Glutamate released by corticostriatal or corticothalamic neurons can act on several types of ionotropic and metabotropic receptors. One of their major effects is to induce an increase in cytosolic $\mathrm{Ca}^{2+}$ which triggers the rapid activation of the extracellular signal-regulated kinase (ERK; Sgambato et al., 1998; Vanhoutte et al., 1999; Pascoli et al., 2011). ERK is part of a signal transduction module highly conserved among eukaryotes that is involved in the control of many cellular processes including cell growth, differentiation and neuronal plasticity (Thomas and Huganir, 2004). This module comprises three enzymes acting in a cascade 


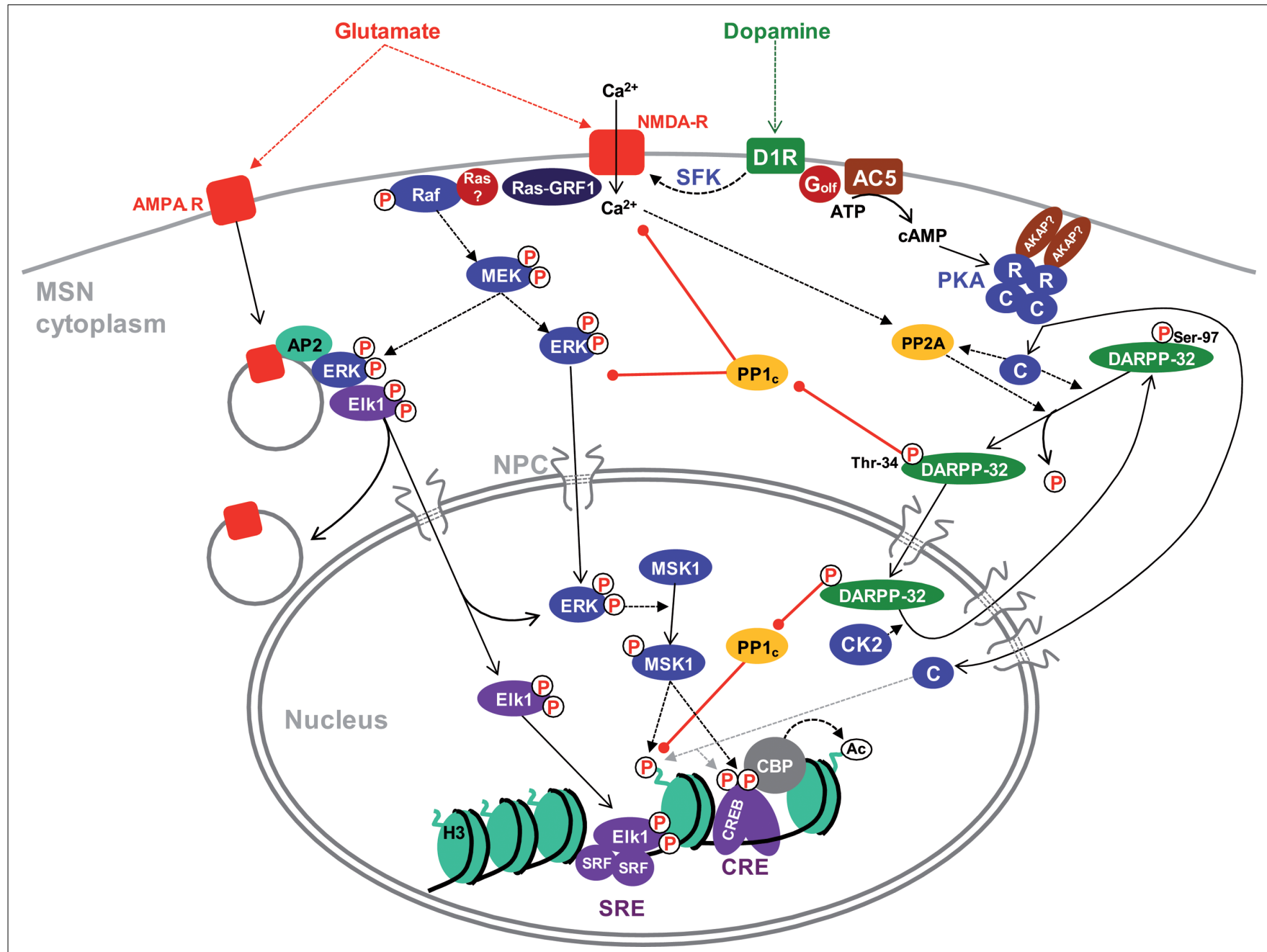

FIGURE 1 | Cytonuclear signaling pathways in MSNs. The indicated pathways have mostly been identified in D1R-expressing MSNs, although similar cascades exist in D2-expressing cells with some differences (Bertran-Gonzalez et al., 2009). The precise location of involved receptors (i.e., perikaryon vs dendrites and spines) is not indicated because it has not been determined experimentally in most cases. Activation of ERK by glutamate involves increases in cytosolic $\mathrm{Ca}^{2+}$ which stimulates Ras-GRF1 and possibly other guanine nucleotide exchange factors. A major source of $\mathrm{Ca}^{2+}$ is the activation of NMDAR by glutamate. This effect is strongly potentiated by stimulation of D1R by dopamine through (i) a cAMP-independent pathway involving Src-family tyrosine kinases (SFK); (ii) an amplification loop with inhibition of PP1 by phospho-Thr-34-DARPP-32. PP1 acts both upstream of ERK (e.g., by dephosphorylating NR1 subunits of NMDAR) and by activating the tyrosine phosphatase STEP which dephosphorylates the regulatory tyrosine of ERK (not shown). In striatal neurons in culture, active ERK associates with endocytosed AMPA-R through adaptor protein 2 (AP2) together with the transcription factor Elk1 and this complex appears to be important for nuclear import of activated ERK and EIk1. D1R activates adenylyl cyclase (mostly AC5 isoform) through the stimulatory heterotrimeric $\mathrm{G}_{\text {olf }}$ protein containing the $\alpha_{\text {olf }}$ and $\gamma 7$ subunits. The inactive PKA heterotetramer is usually anchored through AKAPs, yet to be characterized in MSNs. CAMP binds to the regulatory subunits $(\mathrm{R})$ and releases the catalytic subunits (C). C subunits phosphorylate numerous substrates in the cytoplasm and diffuse to the nucleus where they can phosphorylate proteins such as CREB or histone H3. In MSNs however, a nuclear resident protein kinase, ERK-activated MSK1, plays a major role in CREB and H3 phosphorylation. CREB recruits $\mathrm{CBP}$ which has histone acetyltransferase activity. PKA phosphorylates DARPP-32 on Thr-34, turning it into a potent inhibitor of PP1 catalytic subunit (PP1C). DARPP-32 continuously cycles between the cytoplasm and the nucleus and its nuclear export is facilitated by phosphorylation of Ser-97 by CK2, which is present in the cytoplasm and nucleus of MSNs. PKA increases nuclear DARPP-32 by inducing the dephosphorylation of Ser-97 by PP2A. Dotted arrows indicate influences or catalysis, solid arrows displacement. Red arrows with a round end indicate inhibition. NPC, nuclear pore complex. See text for references. of sequential activatory phosphorylation: the upstream kinases (MAPK/ERK-kinase-kinases, MEKKs) phosphorylate and activate the MAPK/ERK-kinases (MEKs). MEKs are dual specificity kinases that trigger the activation of MAPKs by phosphorylating a threonine (Thr) and a tyrosine (Tyr) residue in their activation loop. In the striatum, it is well documented that drugs of abuse that share the capacity to increase extracellular DA levels (Di Chiara et al., 1998), induce a robust increase in ERK phosphorylation in MSNs (Valjent et al., 2000, 2004). Activation of the ERK pathway requires D1R (Valjent et al., 2000, 2004, 2005) and is antagonized by D3R in regions where this receptor is expressed (Zhang et al., 2004). Interestingly, ERK activation 
appears to be also dependent on glutamate $N$-methyl-D-aspartate receptors (NMDARs) since antagonists for these receptors block ERK phosphorylation in MSNs (Valjent et al., 2000, 2001, 2005). This provides the basis for coincidence detection between the DA and glutamate pathways, which is predicted to specifically identify neurons activated in relation to rewarding stimuli (Girault et al., 2007). Several molecular mechanisms of interaction between D1R and NMDAR converge for this effect (Figure 1): (i) a PKAindependent pathway involving Src-family non-receptor tyrosine kinases (Pascoli et al., 2011); (ii) a cAMP-PKA mediated effect through inhibition of the serine/threonine phosphatase PP1 (see below) and of the striatal-enriched tyrosine phosphatase STEP (Valjent et al., 2005). Activation of the ERK pathway in response to $\mathrm{Ca}^{2+}$ influx in MSNs results to a large extent from the activation of a $\mathrm{Ca}^{2+}$ /calmodulin-regulated guanine nucleotide exchange factor (GEF) termed Ras-guanine nucleotide releasing factor 1 (RasGRF1; Fasano et al., 2009). In addition, two other GEFs, stimulated by calcium and diacylglycerol, CalDAG-GEFI and CalDAG-GEFII (also known as RasGRP1/2) are expressed in MSNs and likely to be involved in the control of the ERK pathway (Toki et al., 2001).

Besides the PKA and ERK pathways, other signaling cascades are likely to be involved in the regulation of nuclear functions but have received comparatively less attention so far in striatal neurons. They include the $\mathrm{Ca}^{2+} /$ calmodulin-activated protein kinases (CaMKs) which play a key role in the regulation of gene expression in other neuronal types (Deisseroth and Tsien, 2002; Cohen and Greenberg, 2008). CaMKII is implicated in the activation of ERK (see Wang et al., 2007 for a review) and CaMKIV, which is predominantly nuclear, negatively regulates responses to cocaine in the MSNs (Bilbao et al., 2008).

\section{THE ROLE OF PROTEIN PHOSPHATASES IN SIGNALING IN MSNS}

The phosphorylation state of PKA and ERK substrates also depends on the activity of serine/threonine protein phosphatases. Well-characterized protein phosphatases in the striatum include protein phosphatase 1 (PP1 or PPP1), 2A (PP2A or PPP2) and 2B (PP2B or calcineurin or PPP3). PP1 catalytic subunit (PP1c) is a $\sim 36 \mathrm{kDa}$ globular protein highly conserved in eukaryotes. Among the four PP1c isoforms $(\alpha, \beta / \delta, \gamma 1$, and $\gamma 2)$ expressed in the mammalian brain, $\mathrm{PP} 1 \alpha$ and $\mathrm{PP} 1 \gamma 1$ are highly expressed in the striatum, whereas $\mathrm{PP} 1 \beta / \delta$ is less abundant (Da Cruz e Silva et al., 1995). PP1c subcellular localization and substrate specificity are controlled by multiple targeting subunits, which regulate its activity in combination with endogenous inhibitors (Bollen et al., 2010). DA- and cAMP-regulated phosphoprotein $\mathrm{Mr}$ 32,000 (DARPP-32 or PPP1 regulatory subunit 1B - PPP1R1B) is an endogenous inhibitor of PP1 particularly enriched in striatal MSNs (Walaas et al., 1983; Hemmings et al., 1984; Ouimet et al., 1984). DARPP-32 activity is modulated by multiple neurotransmitters and is involved in the response to many neurotransmitters and psychoactive drugs (Svenningsson et al., 2004). Phosphorylation of specific Thr and serine (Ser) residues determines DARPP32 overall function. For instance, phosphorylation of Thr-34 by PKA or cGMP-dependent protein kinase turns DARPP-32 into a very potent inhibitor of PP1c (Hemmings et al., 1984). Inhibition of PP1c by DARPP-32 amplifies PKA signaling by enhancing the phosphorylation of those of its targets that are substrates of
PP1, constituting a positive feed-forward mechanism by which the D1R DA signal is amplified (Svenningsson et al., 2004). DARPP32 is also involved in cross-talks between signaling pathways and appears to be essential for ERK activation in response to drugs of abuse, as this activation is prevented in DARPP-32 knockout and in knockin Thr-34-Ala point mutant mice (Valjent et al., 2005). Altogether, the dopamine-dependent activation of the phosphatase inhibitor DARPP-32, directly or indirectly amplifies both PKA and ERK signaling cascades in MSNs.

\section{BASIC MECHANISMS OF PROTEIN TRAFFIC BETWEEN THE CYTOPLASM AND THE NUCLEUS}

Stimuli-triggered signaling cascades can promote the relocalization of effector molecules from the cytoplasm to the nucleus where they exert direct or indirect effects on the expression of specific target genes. Conversely, termination of nuclear signaling can be facilitated by an efficient export of nuclear factors out of the nucleus. Thus, nuclear traffic provides a means of temporal and spatial control of signaling cascades and is tightly regulated by numerous mechanisms and at multiple levels (see Kaffman and O'Shea, 1999; Poon and Jans, 2005; Terry et al., 2007, for reviews). Because it is central for understanding cytonuclear signaling, we briefly overview the basic principles of nuclear import and export mechanisms, although this knowledge has been acquired in other cell types and little is known about the possible specificities of striatal neurons in this matter.

\section{THE NUCLEAR PORE COMPLEX}

Cytonuclear traffic takes place through the nuclear pore complex (NPC) that mediates bidirectional transport between the cytoplasm and the nucleus (Hoelz et al., 2011). The nuclear pore complex is a huge macromolecular assembly (diameter $\sim 100 \mathrm{~nm}$ ) that penetrates the double lipid bilayer of the nuclear envelope and is constructed by multiple copies of $\sim 30$ different proteins called nucleoporins, functionally conserved from yeast to mammals. Interestingly, a point mutation of nucleoporin-62 (Nup62) is responsible for a rare autosomal recessive infantile bilateral striatal necrosis (Basel-Vanagaite et al., 2006), although the mechanisms of the lesions and the basis for their striatal specificity are not known. Diffusion channels through the NPC have a calculated diameter of $\sim 9-10 \mathrm{~nm}$ and allow the free passage of macromolecules of up to $\sim 40 \mathrm{kDa}$ (Hoelz et al., 2011). A diffusion barrier is formed by extended natively unfolded nucleoporin segments that contain numerous Phe-Gly repeats (Patel et al., 2007). This barrier prevents free diffusion of molecules larger than $40 \mathrm{kDa}$ through the NPC. Translocation of such molecules is an energy-dependent process mediated by soluble transport receptors belonging to the family of the karyopherins, which interact with the Phe-Gly repeats through poorly understood mechanisms, and with specific sequences on their cargoes (see Mosammaparast and Pemberton, 2004; Hoelz et al., 2011, for reviews). Members of the karyopherin- $\beta$ (Kap $\beta)$ family, which share some sequence and structure homologies, are also termed importins and exportins depending on whether they mediate import into or export out of the nucleus, respectively. Kap $\beta$ proteins bind to their cargoes via specific recognition of amino acid targeting sequences termed nuclear localization signal (NLS) for nuclear import and nuclear export signal (NES) 
for export (Xu et al., 2010; Figure 2). Both importins and exportins interact with the small G-protein Ran, which, in its intranuclear GTP-bound form, induces dissociation of importin complexes and association of cargoes with exportin (Pemberton and Paschal, 2005).

\section{NUCLEAR IMPORT AND EXPORT}

The nuclear import cycle is mostly driven by a heterodimeric carrier composed by importin- $\beta(\operatorname{Imp} \beta)$ and its adaptor importin- $\alpha$ (Imp $\alpha$, a member of karyopherin- $\alpha$ family). Imp $\alpha$ interact with their cargo through classical NLSs which contain one (monopartite) or two (bipartite) clusters of basic residues separated by 10-12 variable residues (Xu et al., 2010). Imp $\beta$ can also bind directly some cargoes (Pemberton and Paschal, 2005). In the cytoplasm, Imp $\alpha$ binds the cargo and forms a heterodimeric complex with $\operatorname{Imp} \beta$. The carrier-cargo complex then docks on the near cytoplasmic side of the NPC and exchanges sequential, low-affinity interactions with nucleoporins that allow the complex to advance through the NPC to the nucleoplasm by a mechanism still poorly understood. In the nucleus, Imp $\alpha / \beta$-cargo complex dissociates when RanGTP binds $\operatorname{Imp} \beta$, releasing the cargo from the transport complex (Lee et al., 2005). Multiple mechanisms for regulation of nuclear import have been described (see Poon and Jans, 2005; Nardozzi et al., 2010, for reviews). Interestingly, importins have been localized to distal axons and dendrites in several types of neurons, including Aplysia sensory motor neurons, and rodent hippocampal and sensory neurons (Hanz et al., 2003; Thompson et al., 2004). Moreover, recent work has indicated that importin-mediated transport plays a specialized role in neurons in which it not only translocates proteins from the cell soma to the nucleus, but also carries signals from distal compartments to the nucleus during development, as well as in the adult nervous system (Jordan and Kreutz, 2009). Several studies have shown how signals such as $\operatorname{Imp} \beta$ : $\operatorname{cargo}$ complexes, kinases and transcription factors move to the nucleus upon synaptic activation (Martin et al., 1997; Meffert et al., 2003). In the striatum the levels of Imp $\alpha-1$ are increased following lesion of DA neurons (Wang et al., 2004), but the significance of this observation is not known.

The best-characterized nuclear export pathway is mediated by the chromosome region maintenance 1 protein (CRM1; also known as exportin-1), although CRM1-independent pathways have been identified for various cargoes (Lischka et al., 2001; Chen et al., 2004;

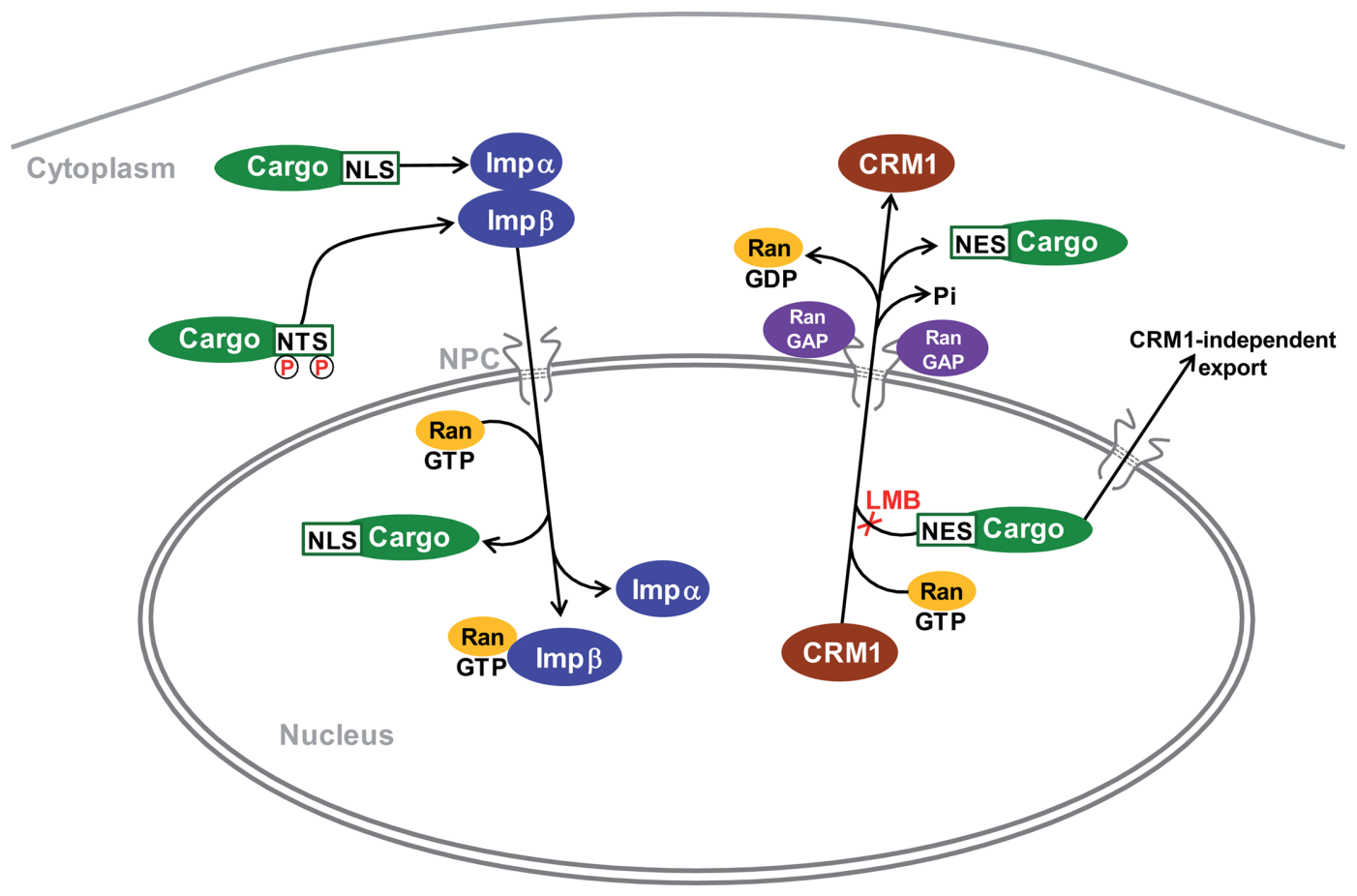

FIGURE 2 | Mechanisms for import and export of proteins to and from the nucleus. The major identified cytonuclear traffic pathways have been characterized in non-neuronal cells and their specifics in MSNs are not known. Transport is mediated by karyopherins which are also known as importins (Imp) and exportins, depending on their function. Proteins are imported by binding to Imp $\alpha$ through a basic nuclear localization sequence (NLS). Some others bind directly to $\operatorname{Imp} \beta$. For example, proteins with nuclear translocation sequence (NTS Ser/Thr-Pro-Ser/Thr), which is activated by phosphorylation, bind to Imp7 (Chuderland et al., 2008). The complex moves through the nuclear pore complex (NPC) to the nucleoplasm where its dissociation is induced by RanGTP. The best-characterized nuclear export pathway is mediated by the exportin CRM1. Proteins containing a hydrophobic nuclear export sequence (NES) bind to CRM1 in the presence of RanGTP. Following translocation the complex is dissociated through hydrolysis of GTP by Ran GTPase-activating proteins (Ran GAPs) enriched on the cytoplasmic side of the NPC. Leptomycin B (LMB) prevents binding of NES to CRM1. CRM1-independent export pathways are poorly characterized. RanGDP is imported from the cytoplasm to the nucleus where GDP is replaced by GTP by specific guanine nucleotide exchange factors (GEFs, not shown). Following carrier-cargo dissociation, the empty importins or exportins return to their compartment of origin through specific pathways that are not indicated on the scheme. References can be found in the text and in (Pemberton and Paschal, 2005; Poon and Jans, 2005; Nardozzi et al., 2010) 
Eulalio et al., 2006; Figure 2). The majority of CRM1 export substrates contain a NES that consists in a short amino acid sequence of regularly spaced hydrophobic residues, of which leucine is the most abundant (Xu et al., 2010). CRM1 binds cooperatively to RanGTP and its export cargo, leading to the formation of a trimeric transport complex in the nucleus that is translocated through the NPC to the cytoplasm (Askjaer et al., 1998). RanGTP within the export complex is hydrolyzed by specific nucleoporins with GTPase-activating properties (Ran-GAPs), allowing dissociation of the export complex on the cytoplasmic side of the NPC (Pemberton and Paschal, 2005). The antifungal antibiotic leptomycin B (LMB) is a powerful tool to distinguish bona fide CRM1-exported substrates among other leucine-rich proteins since it specifically inhibits CRM1 nuclear export by occupation of the NES binding site (Kudo et al., 1999). The use of LMB has thus revealed that many proteins undergo a permanent cytonuclear trafficking and that their apparent cytoplasmic localization results from their nuclear export being more efficient than their import. This dynamic equilibrium can be the target of many regulations. In the next sections we will examine how such regulations apply to signaling proteins important in the striatum, using mostly information obtained in other cell types since very few studies have addressed directly these issues in MSNs.

\section{NUCLEAR TRANSLOCATION OF PROTEIN KINASES IMPORTANT FOR SIGNALING IN MSNs PKA NUCLEAR TRANSLOCATION}

Inactive PKA is a tetrameric holoenzyme consisting of two regulatory subunits $(\mathrm{R})$ that bind and inhibit two catalytic subunits $(\mathrm{C}$; Taylor et al., 1990). The interaction of $\mathrm{R}$ with $\mathrm{C}$ subunits stabilizes both molecules against proteolysis. A family of functionally related proteins known as A-kinase-anchoring proteins (AKAPs) plays an essential role in the distribution of PKA in specific intracellular domains (Wong and Scott, 2004). AKAPs are multivalent adaptor proteins that bind the R subunit of PKA and anchor the enzyme at distinct subcellular locations in close proximity to specific substrates and other signaling enzymes. Sequential and cooperative binding of cAMP to the two sites of each $\mathrm{R}$ subunit releases monomeric C subunits (Taylor et al., 2008; Figure 1). Dissociated $\mathrm{C}$ subunits can then phosphorylate Ser and Thr residues in numerous proteins containing the consensus amino acid sequence $\left(\mathrm{R} / \mathrm{K}_{2}-\mathrm{x}-\mathrm{S} / \mathrm{T}-\Phi\right.$, where $\Phi$ is a hydrophobic residue). PKA can thus exert its function via a wide range of substrates spanning multiple neuronal compartments.

Although PKA is preferentially located in the cytoplasm in resting conditions, a significant fraction of the dissociated $\mathrm{C}$ subunit of PKA localizes to the nucleus upon increase of intracellular cAMP (Meinkoth et al., 1990). The cytoplasmic localization of PKA holoenzyme is achieved by tethering the R subunits to cytoplasmic AKAPs. In addition the quaternary complex is too big to diffuse into the nucleus and no active import mechanism has been described for the holoenzyme. In contrast, free $\mathrm{C}$ subunits can diffuse into the nucleus since they are small enough to pass through the NPC (Meinkoth et al., 1990; Harootunian et al., 1993). A strong and delayed activation of nuclear PKA-mediated phosphorylation is observed in neurons following stimulation of membrane receptors that activate adenylyl cyclase (Gervasi et al., 2007). The functional importance of nuclear PKA was demonstrated using a specific inhibitor of this enzyme in the nucleus, which prevented the induction of long-lasting long-term potentiation in hippocampal slices (Matsushita et al., 2001).

Considering the fact that specific anchoring proteins tightly compartmentalize PKA subcellular localization, it is rather unlikely that PKA activated at the synapse can travel from distant processes to the nucleus. Instead, the rapid diffusion toward the cell body of the highly hydrophilic cAMP produced at the plasma membrane may allow the activation and translocation of PKA located in close proximity to the nucleus (Hempel et al., 1996). In some cell types, a pool of PKA tethered to the nuclear envelope by specific AKAPs is able to rapidly translocate to the nucleus upon cAMP increase (Wong and Scott, 2004). The anchoring of RII $\beta$ to AKAP75, two proteins abundant in specific neuronal populations, appears to be an important factor for nuclear activation of PKA (Paolillo et al., 1999). In addition, nuclear anchoring proteins can retain the free $\mathrm{C}$ subunit of PKA and facilitate its nuclear function (Sastri et al., 2005), whereas binding to the protein kinase inhibitor (PKI) which has a strong NES enhances its active export by a CRM1-dependent mechanism (Fantozzi et al., 1994). However, little is known about the regulation of nuclear dynamics of PKA in neurons, in spite of its functional importance.

\section{ERK NUCLEAR TRANSLOCATION}

In neurons as in other cell types, in the absence of stimulation, ERK is inactive and mostly located in the cytoplasm, in dendrites and perikarya. Following activation of the signaling cascades that lead to MEK and ERK activation, phosphorylated ERK accumulates transiently in the nucleus, where it has important targets. This response has been well characterized in MSNs in vivo, in response to corticostriatal stimulation and drugs of abuse (Sgambato et al., 1998; Valjent et al., 2000). However, the molecular mechanisms controlling ERK localization have been mostly studied in nonneuronal cells. The association with MEK, which bears a NES is an important factor for maintaining ERK in the cytoplasm (Adachi et al., 2000). Passive diffusion of the two ERK isoforms (ERK1 and ERK2) that have a molecular mass of 44 and $42 \mathrm{kDa}$, respectively, is sufficient for their nuclear accumulation (Adachi et al., 1999; Burack and Shaw, 2005). In addition, it has been proposed that homodimerization was an important step for ERK nuclear import (Khokhlatchev et al., 1998; Adachi et al., 1999). However, recent studies using FRET and dimerization-deficient mutants have ruled out this hypothesis (Burack and Shaw, 2005; Lidke et al., 2010). ERK sequence does not contain any classical NLS, but includes a novel nuclear translocation signal (NTS) motif, Ser/Thr-Pro-Ser/Thr, which is active when phosphorylated by a variety of protein kinases, and mediates interaction with importin7 (Chuderland et al., 2008). Interestingly, in hippocampal neurons, ERK nuclear translocation appears to require a combination of $\mathrm{Ca}^{2+}$ and cAMP (Impey et al., 1998) or PKA and TrkB signaling (Patterson et al., 2001). Although the mechanism of this synergism is not known, it could reflect the existence of regulatory phosphorylation, yet to be identified. 


\section{TARGETS OF NUCLEAR SIGNALING IN MSNs}

The major nuclear target of signaling pathways in post-mitotic cells is the transcription machinery. Since the first studies on growth factor-regulated transcription in non-neuronal cells (Cochran et al., 1983), it is usual to differentiate immediate-early genes (IEGs) that are rapidly transcribed in response to stimuli and whose transcription does not require protein synthesis. The promoters of these genes contain specific response elements that are targeted by transcription factors regulated by various signaling pathways. Many IEGs are themselves transcription factors and their up-regulation accounts for the induction of late genes. Late genes are transcribed after a longer delay after the onset of the stimulus and their transcription is prevented by protein synthesis inhibitors that prevent IEGs translation. Thus, regulation of transcription includes changes in the levels, localization, and activity of transcription factors, as well as functionally associated alterations in chromatin structure and organization, which can either facilitate or inhibit the expression of specific genes. Some chromatin alterations are long-lasting and may be involved in stable neuronal adaptations. It should be emphasized that regulation of other types of nuclear functions may also be important in neurons such as RNA processing, including mRNA splicing. However, virtually nothing is known about the regulation of these nuclear processes in striatal neurons.

\section{REGULATION OF TRANSCRIPTION FACTORS IN MSNS}

The accumulation of active PKA and/or P-ERK in the nucleus leads to phosphorylation of several nuclear proteins involved in gene transcription. In neurons the most extensively studied transcription factor substrate of PKA is the cAMP responseelement (CRE) binding protein (CREB). CREB is a member of the leucine-zipper transcription factors family that bind to a specific DNA sequence, CRE, found in one or several copies in the promoters of many genes (Shaywitz and Greenberg, 1999). CREB dimer binds constitutively to CRE sites, but is inactive. Its activity increases when it is phosphorylated on Ser-133, allowing its interaction with the co-activator CREB binding protein (CBP) or the related p300 (Goodman and Smolik, 2000). CBP mutations are responsible for Rubinstein-Taybi syndrome, a rare human genetic disorder characterized by mental retardation and physical abnormalities (Petrij et al., 1995). CBP possess a histone acetyl transferase (HAT) activity and interacts with the basic transcriptional machinery. CREB also interacts with the cAMP-regulated transcriptional co-activators (CRTC1-3, also called transducer of regulated CREB - ToRC - in Drosophila melanogaster; Altarejos and Montminy, 2011). CRTCs are important partners of CREB, activated in response to cAMP and $\mathrm{Ca}^{2+}$, which both promote its nuclear accumulation. Interestingly, CRTC is upregulated in rats chronically treated with cocaine, through the upregulation of microRNA-212 (miR-212; Hollander et al., 2010). In addition to PKA, Ser-133 is the target of many other protein kinases, including CaMK II/IV, p90 ribosomal S6 kinases 1/2 (RSK1/2), mitogen- and stress-activated kinases 1/2 (MSK1/2), and PKC (Johannessen and Moens, 2007). MSK1 is a nuclear substrate of ERK (Deak et al., 1998) enriched in the striatum (Heffron and Mandell, 2005). The role of MSK1 in CREB regulation in MSNs seems to be prominent since in mutant mice lacking MSK1 many biochemical nuclear responses in response to cocaine, including CREB phosphorylation, were blocked and locomotor sensitization was decreased (Brami-Cherrier et al., 2005). In contrast, Zif-268 induction and cocaine conditioned place preference were not altered. Importantly, $\Delta$ FosB, a cocaineinduced transcription factor that is expressed at low levels following a single drug administration, but accumulates after repeated treatment due to its stability, plays a major role in morphological and behavioral responses to chronic cocaine (Nestler, 2008).

The transcription factor Elk1, a member of the Ets family, associates with two molecules of serum response factor (SRF) to form a ternary complex which binds to serum response elements (SRE) found in the promoter of many genes (Besnard et al., 2010; Figure 1). In MSNs Elk-1 is located in part in the cytoplasm and its nuclear accumulation depends on its phosphorylation by ERK (Vanhoutte et al., 1999). Moreover, ERK and Elk1 appear to be recruited from neurites to cell bodies and nucleus in response to glutamate stimulation, and to undergo retrograde trafficking with $\alpha$-amino-3-hydroxy-5-methyl-4-isoxazolepropionic acid (AMPA) receptors, following their clathrin-dependent endocytosis (Trifilieff et al., 2009; Figure 1). This interesting mechanism could provide an example of synapse-to nucleus signaling, although this remains to be directly demonstrated.

In addition to the ERK-mediated pathways, it should be mentioned that stimulation of D1R induces gene transcription through activation of L-type calcium channels and recruitment of the $\mathrm{Ca}^{2+} /$ calcineurin-regulated nuclear factor of activated $\mathrm{T}$ cells (NFAT; Groth et al., 2008). A different type of cytoplasmic transcription factor which accumulates in the nucleus upon binding of its ligand, the glucocorticoid receptor (GR), also plays an important role in responses mediated by striatal neurons. Selective deletion of GR in neurons expressing the D1R promoter resulted in altered gene expression and behavioral responses induced by cocaine but not morphine (Barik et al., 2010). Many other transcription factors are likely to be important for controlling gene expression in MSNs but have so far received less attention.

\section{REGULATION OF CHROMATIN REMODELING IN MSNS}

Signaling in the nucleus not only controls the activity of transcription factors that mediate gene expression, but also changes chromatin structure thereby modifying the transcriptional rate of specific genes. Histones can undergo multiple post-translational modifications on their N-terminal tail, including phosphorylation, acetylation, methylation, ubiquitinylation, and sumoylation, which alter their interaction with DNA, and thus the degree of chromatin condensation (see Shilatifard, 2006 for a review). Transition from condensed chromatin into a more relaxed state is needed to accommodate the molecular elements required for transcription. Chromatin remodeling is involved in many processes in the nervous system, during development and differentiation, but also learning and memory (Levenson and Sweatt, 2005). Recent research indicates that alterations of histone posttranslational modifications may also be implicated in psychiatric disorders, including depression, schizophrenia, and drug addiction (Tsankova et al., 2007; Borrelli et al., 2008; Brami-Cherrier et al., 2009; Franklin and Mansuy, 2010). 
Phosphorylation of histone H3 on Ser-10 is the most extensively studied chromatin post-translational modification in striatal neurons. The functional significance of this modification is not entirely clear however. It has been suggested that during the interphase, phosphorylation of $\mathrm{H} 3$ Ser-10 promotes detachment of specific regions from the heterochromatic scaffold to allow decondensation and gene expression (Johansen and Johansen, 2006). Ser-10 phosphorylation in combination with H3 Lys-14 methylation is associated with increased $c$-Fos transcription in hippocampal neurons in response to stimulation of various receptors including D1R (Crosio et al., 2003). Phosphorylation of H3 is increased in striatal neurons after acute treatment with cocaine, a response that requires MSK1 (Brami-Cherrier et al., 2005) and occurs selectively in striatonigral neurons (Bertran-Gonzalez et al., 2008). Importantly, chromatin immunoprecipitation (ChIP) demonstrated that this phosphorylation occurred specifically at the promoter region of IEGs (Kumar et al., 2005) through recruitment of CBP (Levine et al., 2005). Similar responses were observed in striatonigral neurons following L-DOPA treatment in dopamine-denervated striatum (Santini et al., 2007, 2009). Conversely, in striatopallidal neurons it is the blockade of D2 receptors which triggers H3 Ser-10 phosphorylation by unmasking the stimulation of the PKA pathway by A2a adenosine receptors, normally inhibited by D2R (Li et al., 2004; Bertran-Gonzalez et al., 2008, 2009). In this case, phosphorylation of H3 Ser-10 is not mediated by MSK1, and may depend directly on PKA and PP1 inhibition by DARPP-32. Additional modifications of $\mathrm{H} 3$ and $\mathrm{H} 4$ tails have been reported in similar conditions (Li et al., 2004; Brami-Cherrier et al., 2005; Kumar et al., 2005; Nicholas et al., 2008).

Recent work further supports the role of covalent modifications of histones in the long-lasting effect of cocaine and possibly other addictive drugs (LaPlant and Nestler, 2011). Genome-wide studies using ChIP with antibodies for polyacetylated $\mathrm{H} 3$ or $\mathrm{H} 4$, or dimethylated $\mathrm{H} 3$ revealed changes in numerous genes including a group of deacetylases, the sirtuins (Renthal et al., 2009). This study emphasized the breadth of drug-induced gene regulation and the interest of genome-wide studies in this context. Repeated cocaine administration reduced global levels of H3 Lys-9 dimethylation in the nucleus accumbens, through the repression of the G9a lysine dimethyltransferase in this brain region by $\Delta$ FosB (Maze et al., 2010). Using conditional mutagenesis and viral-mediated gene transfer, the authors found that G9a down-regulation increased the dendritic spine plasticity of nucleus accumbens MSNs and enhanced the preference for cocaine. Interestingly, di- and trimethylation of H3 Lys-9 create binding sites for chromodomain-containing proteins, including those of the heterochromatin protein 1 (HP1) family which promote transcriptional repression and genomic silencing (Bannister et al., 2001; Lachner et al., 2001). Accordingly, altered H3 Lys-9 trimethylation induced in the nucleus accumbens by repeated cocaine administration was associated with changes in heterochromatin (Maze et al., 2011). Overexpression in the ventral striatum of Setdb1 (Set domain, bifurcated 1), a methyltransferase specific for H3 Lys-9, down-regulated the expression of NR2B (Jiang et al., 2010). All these results identify regulation of H3 Lys-9 methylation as functionally important in the striatum.
DNA methylation on cytidine residues, preferentially located in CpG islands, is classically considered to be a very stable mark. However, in brain neurons DNA methylation appears to be reversible and to participate in memory formation and storage (Day and Sweatt, 2010). A recent work provides a possible mechanism for demethylation in this context, through a process that requires the base excision repair pathway (Guo et al., 2011). This involves a specific hydroxylase, TET1, which converts 5-methylcytosine to 5-hydroxymethylcytosine, which exists at significant levels in various brain regions (Kriaucionis and Heintz, 2009). The importance of DNA methylation in the striatum is indicated by the role of the methylase Dnmt3 in cocaine-induced spine alterations (LaPlant et al., 2010). Moreover the X-linked transcriptional repressor methyl $\mathrm{CpG}$ binding protein 2 (MeCP2), known for its role in a neurodevelopmental disorder, the Rett syndrome, regulates cocaine intake in rat ( $\mathrm{Im}$ et al., 2010). This effect seems to depend on regulation of striatal BDNF levels in interaction with miR-212 (Im et al., 2010), which is itself upregulated by chronic cocaine, as mentioned above (Hollander et al., 2010). Moreover, amphetamine-induced spine plasticity and conditioned place preference were altered in MeCP2-deficient mice (Deng et al., 2010). Altogether these observations strongly support the importance of chromatin post-translational modifications and DNA methylation in the chronic effects of drugs of abuse in striatal neurons and suggest they may also be important for the long-lasting adaptations of these neurons in physiological or other pathological circumstances.

\section{ROLE OF PROTEIN PHOSPHATASES IN THE REGULATION OF CHROMATIN RESPONSES IN MSNS}

We have discussed above several protein kinases pathways which converge to the nucleus of MSNs where they control transcription factors. These pathways can also directly alter the state of phosphorylation of histones and other nuclear proteins including enzymes regulating the modifications of histones or DNA. The resulting changes in transcription can in turn have consequences on chromatin structure, as indicated by the effects of chronic drug treatments on the levels of several mRNAs coding for these enzymes (LaPlant et al., 2010; Maze et al., 2010). However much remains to be done to better understand these regulations. Recent work has uncovered the likely importance of the regulation of nuclear protein phosphatases in striatal neurons. The role of nuclear protein phosphatases has been extensively studied in non-neuronal tissues where these enzymes have been implicated in the regulation of multiple processes including gene transcription, RNA processing, cell cycle progression or signal termination (Bollen and Beullens, 2002; Moorhead et al., 2007). For example, PP1 is a major P-CREB phosphatase (Hagiwara et al., 1992) and regulates the dephosphorylation of P-Ser-10 H3 in mitotic cells (Hsu et al., 2000). Regulation of PP1 activity in the nucleus of hippocampal neurons alters histone post-translational modifications directly (phosphorylation) and indirectly through the control enzymes that modify acetylation and methylation, as well as CREB expression and phosphorylation associated with learning and memory (Koshibu et al., 2009). PP1 $\alpha$ appears to be the predominant PP1 isoform in the nucleus of MSNs (Ouimet et al., 1995), where it has the potential to antagonize the action of 
dopamine and glutamate by dephosphorylating PKA and ERK targets. Recent work shows that PP1 activity can be modulated in the nucleus of MSNs through the regulated accumulation of phospho-Thr-34-DARPP-32 (Stipanovich et al., 2008). This study demonstrated that psychostimulant drugs (d-amphetamine and cocaine) and morphine, which act by different mechanisms but share the ability to increase extracellular dopamine in the striatum, as well as incentive learning, increased the nuclear concentration of DARPP-32. In vitro analysis of the mechanisms of DARPP32 nuclear translocation showed that this protein is constantly shuttling between the cytoplasm and the nucleus, although it is predominantly localized in the cytoplasm as a result of an efficient CRM-1-dependent nuclear export (Stipanovich et al., 2008). This export requires phosphorylation of Ser-97 by casein kinase 2 (CK2) present in the nucleus and cytoplasm of MSNs (Figure 1). Upon D1R stimulation, Ser-97 is dephosphorylated, presumably through activation of a PKA-activated form of PP2A (Ahn et al., 2007; Stipanovich et al., 2008), causing a nuclear accumulation of DARPP-32. Ongoing work in our laboratory has revealed that additional mechanisms are involved in the control of DARPP-32 cytonuclear localization, providing the basis for its precise but complex regulation by multiple extracellular signals (Matamales and Girault, unpublished observations). It should be underlined that the control of DARPP-32 localization by regulation of Ser-97 phosphorylation is parallel to but independent from its phosphorylation on Thr-34, which is responsible for PP1 inhibition activity. When P-Thr34 DARPP-32 accumulates in the nucleus, it can facilitate the phosphorylation of histone H3 on Ser-10 (Stipanovich et al., 2008). In contrast, nuclear trapping of dephospho-Thr34-DARPP-32 by mutation of Ser-97 to Ala decreases signaling responses including $\mathrm{H} 3$ phosphorylation (ibid and our unpublished observations). Thus, it is possible that in some circumstances nuclear accumulation of inactive DARPP-32 plays a role in down-regulating cytoplasmic responses, a hypothesis that needs to be explored.

The nuclear accumulation of the active form of a potent PP1 inhibitor may help to tilt the kinase and phosphatase equilibrium in favor of phosphorylation. Given the large number of potential substrates of PP1 in the nucleus, it is likely that the regulation of DARPP-32 trafficking has multiple consequences that have yet to be identified. For example, it has been shown that DARPP-32 binds directly to the splicing factor transformer 2-beta 1 (tra2-beta1) and changes the usage of tra2-betal dependent alternative exons in heterologous systems (Benderska et al., 2010). Therefore the link

\section{REFERENCES}

Adachi, M., Fukuda, M., and Nishida, E. (1999). Two co-existing mechanisms for nuclear import of MAP kinase: passive diffusion of a monomer and active transport of a dimer. EMBO J. 18, 5347-5358.

Adachi, M., Fukuda, M., and Nishida, E. (2000). Nuclear export of MAP kinase (ERK) involves a MAP kinase kinase (MEK)-dependent active transport mechanism. J. Cell Biol. 148, 849-856.

Adams, J. P., and Dudek, S. M. (2005). Late-phase long-term potentiation:

between the nuclear localization of DARPP-32 and short term and long-term adaptations, including but not restricted to changes in gene transcription, clearly needs to be further investigated.

\section{CONCLUSION AND PERSPECTIVES}

We have provided here an overview of some mechanisms of cytonuclear signaling and regulation of nuclear functions and summarized the current knowledge of glutamate and dopamine signaling to the nucleus in MSNs (Figure 1). Much of our understanding of the basic mechanisms of cytonuclear signaling is inferred from work in other cellular systems since few studies have dissected the mechanisms and regulation of these pathways in striatal neurons so far. As a general principle the prevention of "background noise" kinase activity in the nucleus of unstimulated neurons is likely to be important to avoid meaningless nuclear responses. This is probably achieved through the regulated cytoplasmic sequestration of PKA, ERK, and other signaling molecules including some transcription factors, as well as by potent phosphatase activities in the nucleus. Upon receptor stimulation, and resulting cAMP and $\mathrm{Ca}^{2+}$ production, protein kinases are activated and accumulate in the nucleus, where they exert their effects directly or indirectly through resident nuclear kinases such as MSK1. Identified targets include transcription factors and chromatin components such as histones that modulate the rate of transcription. The silencing of phosphatase activity through activation and regulated nuclear translocation of the PP1 inhibiting form of DARPP-32 plays a complementary role in MSNs. Thus, the precise nuclear adaptations taking place in MSNs are likely to depend on a fine balance between multiple cytonuclear signaling pathways. Since the nuclear responses are important for long-term changes of behavioral responses we suggest that deciphering the rules of cytonuclear signaling in striatal neurons will be crucial to understand the learning mechanisms that involve the basal ganglia and their pathological alterations. This new field is only beginning to be explored in this context.

\section{ACKNOWLEDGMENTS}

Work in J. A. Girault's laboratory is supported by Inserm and UPMC and by grants from the Fondation pour la recherche médicale (FRM), the Agence Nationale de la Recherche (ANR), the Fondation pour la Recherche sur le cerveau (FRC), and the European Research Council. The group is affiliated to the Ecole des Neurosciences de Paris Ile de France (ENP). M. Matamales is currently supported by an EMBO Long-Term Fellowship (ALTF 1228-2010).

Askjaer, P., Jensen, T. H., Nilsson, J. Englmeier, L., and Kjems, J. (1998). The specificity of the CRM1-Rev nuclear export signal interaction is mediated by RanGTP. J. Biol. Chem. 273, 33414-33422.

Bannister, A. J., Zegerman, P., Partridge, J. F., Miska, E. A., Thomas, J. O., Allshire, R. C., and Kouzarides, T. (2001). Selective recognition of methylated lysine 9 on histone $\mathrm{H} 3$ by the HP1 chromo domain. Nature 410, 120-124.

Barik, J., Parnaudeau, S., Saint Amaux, A. L., Guiard, B. P., Golib Dzib, J. F.,
Bocquet, O., Bailly, A., Benecke, A. and Tronche, F. (2010). Glucocorticoid receptors in dopaminoceptive neurons, key for cocaine, are dispensable for molecular and behavioral morphine responses. Biol. Psychiatry 68, 231-239.

Basel-Vanagaite, L., Muncher, L., Straussberg, R., Pasmanik-Chor, M., Yahav, M., Rainshtein, L., Walsh, C. A., Magal, N., Taub, E., Drasinover, V., Shalev, H., Attia, R., Rechavi, G., Simon, A. J., and Shohat, M. (2006). Mutated nup62 causes autosomal recessive infantile bilateral 
striatal necrosis. Ann. Neurol. 60, 214-222.

Beaulieu, J. M., Sotnikova, T. D., Marion, S., Lefkowitz, R. J., Gainetdinov, R. R., and Caron, M. G. (2005). An Akt/beta-arrestin 2/PP2A signaling complex mediates dopaminergic neurotransmission and behavior. Cell 122, 261-273.

Benderska, N., Becker, K., Girault, J. A., Becker, C. M., Andreadis, A., and Stamm, S. (2010). DARPP-32 binds to tra2-betal and influences alternative splicing. Biochim. Biophys. Acta. 1799, 448-453.

Bennett, B. D., and Wilson, C. J. (2000). "Synaptology and physiology of neostriatal neurones," in Brain Dynamics and the Striatal Complex, eds R. Miller and J. Wickens (London: H. A. Publishers), 111-140.

Berger, S. L., Kouzarides, T., Shiekhattar, R., and Shilatifard, A. (2009). An operational definition of epigenetics. Genes Dev. 23, 781-783.

Bertran-Gonzalez, J., Bosch, C., Maroteaux, M., Matamales, M., Herve, D., Valjent, E., and Girault, J. A. (2008). Opposing patterns of signaling activation in dopamine D1 and D2 receptor-expressing striatal neurons in response to cocaine and haloperidol. J. Neurosci. 28, 5671-5685.

Bertran-Gonzalez, J., Hakansson, K., Borgkvist, A., Irinopoulou, T., Brami-Cherrier, K., Usiello, A., Greengard, P., Herve, D., Girault, J. A., Valjent, E., and Fisone, G. (2009). Histone $\mathrm{H} 3$ phosphorylation is under the opposite tonic control of dopamine D2 and adenosine $\mathrm{A} 2 \mathrm{~A}$ receptors in striatopallidal neurons. Neuropsychopharmacology 34, 1710-1720.

Bertran-Gonzalez, J., Herve, D., Girault, J. A., and Valjent, E. (2010). What is the degree of segregation between striatonigral and striatopallidal projections? Front. Neuroanat. 4:136. doi: 10.3389/fnana.2010.00136

Besnard, A., Galan-Rodriguez, B., Vanhoutte, P., and Caboche, J. (2010). Elk-1 a transcription factor with multiple facets in the brain. Front. Neurosci. 5:35. doi: 10.3389/fnins.2011.00035

Bilbao, A., Parkitna, J. R., Engblom, D., Perreau-Lenz, S., Sanchis-Segura, C., Schneider, M., Konopka, W., Westphal, M., Breen, G., Desrivieres, S., Klugmann, M., Guindalini, C., Vallada, H., Laranjeira, R., de Fonseca, F. R., Schumann, G., Schutz, G., and Spanagel, R. (2008). Loss of the $\mathrm{Ca} 2+/$ calmodulindependent protein kinase type IV in dopaminoceptive neurons enhances behavioral effects of cocaine. Proc. Natl. Acad. Sci. U.S.A. 105, 17549-17554.

Black, I. B., Adler, J. E., Dreyfus, C. F., Friedman, W. F., LaGamma, E. F., and Roach, A. H. (1987). Biochemistry of information storage in the nervous system. Science 236, 1263-1268.

Bollen, M., and Beullens, M. (2002). Signaling by protein phosphatases in the nucleus. Trends Cell Biol. 12, 138-145.

Bollen, M., Peti, W., Ragusa, M. J., and Beullens, M. (2010). The extended PP1 toolkit: designed to create specificity. Trends Biochem. Sci. 35, 450-458.

Borrelli, E., Nestler, E. J., Allis, C. D., and Sassone-Corsi, P. (2008). Decoding the epigenetic language of neuronal plasticity. Neuron 60, 961-974.

Brami-Cherrier, K., Roze, E., Girault, J. A., Betuing, S., and Caboche, J. (2009). Role of the ERK/MSK1 signalling pathway in chromatin remodelling and brain responses to drugs of abuse. J. Neurochem. 108, 1323-1335.

Brami-Cherrier, K., Valjent, E., Garcia, M., Pages, C., Hipskind, R. A., and Caboche, J. (2002). Dopamine induces a PI3-kinase-independent activation of Akt in striatal neurons: a new route to cAMP response element-binding protein phosphorylation. J. Neurosci 22, 8911-8921.

Brami-Cherrier, K., Valjent, E., Herve, D., Darragh, J., Corvol, J. C., Pages, C., Arthur, S. J., Girault, J. A., and Caboche, J. (2005). Parsing molecular and behavioral effects of cocaine in mitogenand stress-activated protein kinase1-deficient mice. J. Neurosci. 25, 11444-11454.

Burack, W. R., and Shaw, A. S. (2005). Live cell imaging of ERK and MEK: simple binding equilibrium explains the regulated nucleocytoplasmic distribution of ERK. J. Biol. Chem. 280, 3832-3837.

Chen, T., Brownawell, A. M., and Macara, I. G. (2004). Nucleocytoplasmic shuttling of JAZ, a new cargo protein for exportin-5. Mol. Cell. Biol. 24, 6608-6619.

Chuderland, D., Konson, A., and Seger, R. (2008). Identification and characterization of a general nuclear translocation signal in signaling proteins. Mol. Cell 31, 850-861.

Cochran, B. H., Reffel, A. C., and Stiles, C. D. (1983). Molecular cloning of gene sequences regulated by platelet-derived growth factor. Cell 33, 939-947.

Cohen, S., and Greenberg, M. E. (2008). Communication between the synapse and the nucleus in neuronal development, plasticity, and disease. Annu. Rev. Cell Dev. Biol. 24 183-209.

Corvol, J. C., Studler, J. M., Schonn, J. S., Girault, J. A., and Herve, D. (2001). Galpha(olf) is necessary for coupling D1 and A2a receptors to adenylyl cyclase in the striatum. $J$. Neurochem. 76, 1585-1588.

Creese, I., Sibley, D. R., Hamblin, M W., and Leff, S. E. (1983). The classification of dopamine receptors: relationship to radioligand binding. Annu. Rev. Neurosci. 6, 43-71.

Crosio, C., Heitz, E., Allis, C. D. Borrelli, E., and Sassone-Corsi, P. (2003). Chromatin remodeling and neuronal response: multiple signaling pathways induce specific histone $\mathrm{H} 3$ modifications and early gene expression in hippocampal neurons. J. Cell. Sci. 116 4905-4914.

Da Cruz e Silva, E. F., Fox, C. A., Ouimet, C. C., Gustafson, E., Watson, S. J., and Greengard, P. (1995). Differential expression of protein phosphatase 1 isoforms in mammalian brain. J. Neurosci. 15, 3375-3389.

Day, J. J., and Sweatt, J. D. (2010). DNA methylation and memory formation. Nat. Neurosci. 13, 1319-1323.

Deak, M., Clifton, A. D., Lucocq, L. M. and Alessi, D. R. (1998). Mitogenand stress-activated protein kinase1 (MSK1) is directly activated by MAPK and SAPK2/p38, and may mediate activation of CREB. EMBO J. 17, 4426-4441.

Deisseroth, K., and Tsien, R. W. (2002). Dynamic multiphosphorylation passwords for activitydependent gene expression. Neuron 34, 179-182.

Deng, J. V., Rodriguiz, R. M., Hutchinson, A. N., Kim, I. H., Wetsel, W. C., and West, A. E. (2010). MeCP2 in the nucleus accumbens contributes to neural and behavioral responses to psychostimulants. Nat. Neurosci. 13, 1128-1136.

Diaz, J., Lévesque, D., Lammers, C. H., Griffon, N., Martres, M.-P., Schwartz, J.-C., and Sokoloff, P. (1995). Phenotypical characterization of neurons expressing the dopamine D3 receptor in the rat brain. Neuroscience 65, 731-745.

Di Chiara, G., Tanda, G., Cadoni, C. Acquas, E., Bassareo, V., and Carboni, E. (1998). Homologies and differences in the action of drugs of abuse and a conventional reinforcer (food) on dopamine transmission: an interpretative framework of the mechanism of drug dependence. Adv. Pharmacol. 42, 983-987.
Eulalio, A., Nunes-Correia, I., Carvalho, A. L., Faro, C., Citovsky, V., Salas, J., Salas, M. L., Simoes, S., and de Lima, M. C. (2006). Nuclear export of African swine fever virus p37 protein occurs through two distinct pathways and is mediated by three independent signals. J. Virol. 80, 1393-1404.

Fantozzi, D. A., Harootunian, A. T., Wen, W., Taylor, S. S., Feramisco, J. R., Tsien, R. Y., and Meinkoth, J. L. (1994). Thermostable inhibitor of cAMP-dependent protein kinase enhances the rate of export of the kinase catalytic subunit from the nucleus. J. Biol. Chem. 269, 2676-2686.

Fasano, S., D'Antoni, A., Orban, P. C., Valjent, E., Putignano, E., Vara, H., Pizzorusso, T., Giustetto, M., Yoon, B., Soloway, P., Maldonado, R., Caboche, J., and Brambilla, R. (2009). Ras-guanine nucleotidereleasing factor 1 (Ras-GRF1) controls activation of extracellular signal-regulated kinase (ERK) signaling in the striatum and long-term behavioral responses to cocaine. Biol. Psychiatry 66, 758-768.

Franklin, T. B., and Mansuy, I. M (2010). The prevalence of epigenetic mechanisms in the regulation of cognitive functions and behaviour. Curr. Opin. Neurobiol. 20, 441-449.

Fraser, P., and Bickmore, W. (2007). Nuclear organization of the genome and the potential for gene regulation. Nature 447, 413-417.

Gerfen, C. R., Engber, T. M., Mahan, L. C., Susel, Z., Chase, T. N., Monsma, F. J. Jr., and Sibley, D. R. (1990). D1 and D2 dopamine receptor-regulated gene expression of striatonigral and striatopallidal neurons. Science 250 1429-1432.

Gervasi, N., Hepp, R., Tricoire, L., Zhang, J., Lambolez, B., PaupardinTritsch, D., and Vincent, P. (2007). Dynamics of protein kinase A signaling at the membrane, in the cytosol, and in the nucleus of neurons in mouse brain slices. J. Neurosci. 27, 2744-2750

Girault, J. A., Valjent, E., Caboche, J., and Herve, D. (2007). ERK2: a logical AND gate critical for drug-induced plasticity? Curr. Opin. Pharmacol. 7 , 77-85.

Goelet, P., Castellucci, V. F., Schacher, S., and Kandel, E. R. (1986). The long and the short of long-term memory-a molecular framework. Nature 322, 419-422.

Goodman, R. H., and Smolik, S. (2000). $\mathrm{CBP} / \mathrm{p} 300$ in cell growth, transformation, and development. Genes Dev. 14, 1553-1577. 
Grace, A. A. (1991). Phasic versus tonic dopamine release and the modulation of dopamine system responsivity: a hypothesis for the etiology of schizophrenia. Neuroscience 41, $1-24$.

Greengard, P., Allen, P. B., and Nairn, A. C. (1999). Beyond the dopamine receptor: the DARPP32/protein phosphatase-1 cascade. Neuron 23, 435-447.

Groth, R. D., Weick, J. P., Bradley, K. C., Luoma, J. I., Aravamudan, B., Klug, J. R., Thomas, M. J., and Mermelstein, P. G. (2008). D1 dopamine receptor activation of NFAT-mediated striatal gene expression. Eur. J. Neurosci. 27, 31-42.

Guo, J. U., Su, Y., Zhong, C., Ming, G. L., and Song, H. (2011). Hydroxylation of 5-methylcytosine by TET1 promotes active DNA demethylation in the adult brain. Cell 145, 423-434.

Hagiwara, M., Alberts, A., Brindle, P., Meinkoth, J., Feramisco, J., Deng, T., Karin, M., Shenolikar, S., and Montminy, M. (1992). Transcriptional attenuation following cAMP induction requires $\mathrm{PP}-1$-mediated dephosphorylation of CREB. Cell 70, 105-113.

Hanz, S., Perlson, E., Willis, D., Zheng, J. Q., Massarwa, R., Huerta, J. J., Koltzenburg, M., Kohler, M., van-Minnen, J., Twiss, J. L., and Fainzilber, M. (2003). Axoplasmic importins enable retrograde injury signaling in lesioned nerve. Neuron 40, 1095-1104.

Harootunian, A. T., Adams, S. R., Wen, W., Meinkoth, J. L., Taylor, S. S., and Tsien, R. Y. (1993). Movement of the free catalytic subunit of cAMP-dependent protein kinase into and out of the nucleus can be explained by diffusion. Mol. Biol. Cell 4, 993-1002.

Hasbi, A., Fan, T., Alijaniaram, M., Nguyen, T., Perreault, M. L., O’Dowd, B. F., and George, S. R. (2009). Calcium signaling cascade links dopamine D1-D2 receptor heteromer to striatal BDNF production and neuronal growth. Proc. Natl. Acad. Sci. U.S.A. 106, 21377-21382.

Heffron, D., and Mandell, J. W. (2005). Differential localization of MAPKactivated protein kinases RSK1 and MSK1 in mouse brain. Brain Res. Mol. Brain Res. 136, 134-141.

Hemmings, H. C. Jr., Greengard, P., Tung, H. Y. L., and Cohen, P. (1984). DARPP-32, a dopamineregulated neuronal phosphoprotein, is a potent inhibitor of protein phosphatase-1. Nature 310, 503-505.

Hempel, C. M., Vincent, P., Adams, S. R., Tsien, R. Y., and Selverston, A.
I. (1996). Spatio-temporal dynamics of cyclic AMP signals in an intact neural circuitm. Nature 384, 166-169.

Henikoff, S. (2008). Nucleosome destabilization in the epigenetic regulation of gene expression. Nat. Rev. Genet. 9, 15-26.

Herve, D., Levi-Strauss, M., MareySemper, I., Verney, C., Tassin, J. P., Glowinski, J., and Girault, J. A. (1993). G(olf) and Gs in rat basal ganglia: possible involvement of $\mathrm{G}(\mathrm{olf})$ in the coupling of dopamine D1 receptor with adenylyl cyclase. J. Neurosci. 13, 2237-2248.

Hoelz, A., Debler, E. W., and Blobel, G. (2011). The structure of the nuclear pore complex. Annu. Rev. Biochem. 80, 613-643.

Hollander, J. A., Im, H. I., Amelio, A. L., Kocerha, J., Bali, P., Lu, Q., Willoughby, D., Wahlestedt, C., Conkright, M. D., and Kenny, P. J. (2010). Striatal microRNA controls cocaine intake through CREB signalling. Nature 466, 197-202.

Hsu, J. Y., Sun, Z. W., Li, X., Reuben, M., Tatchell, K., Bishop, D. K., Grushcow, J. M., Brame, C. J., Caldwell, J. A., Hunt, D. F., Lin, R., Smith, M. M., and Allis, C. D. (2000). Mitotic phosphorylation of histone $\mathrm{H} 3$ is governed by Ipl1/aurora kinase and Glc7/PP1 phosphatase in budding yeast and nematodes. Cell 102, 279-291.

Hur, E. M., and Zhou, F. Q. (2010). GSK3 signalling in neural development. Nat. Rev. Neurosci. 11, 539551.

Im, H. I., Hollander, J. A., Bali, P., and Kenny, P. J. (2010). MeCP2 controls BDNF expression and cocaine intake through homeostatic interactions with microRNA-212. Nat. Neurosci. 13, 1120-1127.

Impey, S., Obrietan, K., Wong, S. T., Poser, S., Yano, S., Wayman, G., Deloulme, J. C., Chan, G., and Storm, D. R. (1998). Cross talk between ERK and PKA is required for $\mathrm{Ca} 2+$ stimulation of CREB-dependent transcription and ERK nuclear translocation. Neuron 21, 869-883.

Jiang, Y., Jakovcevski, M., Bharadwaj, R., Connor, C., Schroeder, F. A., Lin, C. L., Straubhaar, J., Martin, G., and Akbarian, S. (2010). Setdb1 histone methyltransferase regulates moodrelated behaviors and expression of the NMDA receptor subunit NR2B. J. Neurosci. 30, 7152-7167.

Johannessen, M., and Moens, U. (2007). Multisite phosphorylation of the cAMP response element-binding protein (CREB) by a diversity of protein kinases. Front. Biosci. 12, 1814-1832.
Johansen, K. M., and Johansen, J. (2006). Regulation of chromatin structure by histone H3S10 phosphorylation. Chromosome Res. 14, 393-404.

Jordan, B. A., and Kreutz, M. R. (2009) Nucleocytoplasmic protein shuttling: the direct route in synapse-tonucleus signaling. Trends Neurosci. 32, 392-401.

Kaffman, A., and O'Shea, E. K. (1999). Regulation of nuclear localization: a key to a door. Annu. Rev. Cell Dev. Biol. 15, 291-339.

Kebabian, J. W., and Calne, D. B. (1979). Multiple receptors for dopamine. Nature 277, 93-96.

Khokhlatchev, A. V., Canagarajah, B., Wilsbacher, J., Robinson, M., Atkinson, M., Goldsmith, E., and Cobb, M. H. (1998). Phosphorylation of the MAP kinase ERK2 promotes its homodimerization and nuclear translocation. Cell 93, 605-615.

Koshibu, K., Graff, J., Beullens, M., Heitz, F. D., Berchtold, D., Russig, H., Farinelli, M., Bollen, M., and Mansuy, I. M. (2009). Protein phosphatase 1 regulates the histone code for long-term memory. J. Neurosci. 29, 13079-13089.

Kreitzer, A. C. (2009). Physiology and pharmacology of striatal neurons. Annu. Rev. Neurosci. 32, 127-147.

Kriaucionis, S., and Heintz, N. (2009). The nuclear DNA base 5-hydroxymethylcytosine is present in Purkinje neurons and the brain. Science 324, 929-930.

Kudo, N., Matsumori, N., Taoka, H. Fujiwara, D., Schreiner, E. P., Wolff, B., Yoshida, M., and Horinouchi, S. (1999). Leptomycin B inactivates CRM1/exportin 1 by covalent modification at a cysteine residue in the central conserved region. Proc. Natl. Acad. Sci. U.S.A. 96, 9112-9117.

Kumar, A., Choi, K. H., Renthal, W. Tsankova, N. M., Theobald, D. E., Truong, H. T., Russo, S. J., Laplant, Q., Sasaki, T. S., Whistler, K. N., Neve, R. L., Self, D. W., and Nestler, E. J. (2005). Chromatin remodeling is a key mechanism underlying cocaineinduced plasticity in striatum. Neuron 48, 303-314.

Lachner, M., O'Carroll, D., Rea, S., Mechtler, K., and Jenuwein, T. (2001). Methylation of histone H3 lysine 9 creates a binding site for HP1 proteins. Nature 410, 116-120.

LaPlant, Q., and Nestler, E. J. (2011). CRACKing the histone code: cocaine's effects on chromatin structure and function. Horm. Behav. 59, 321-330.

LaPlant, Q., Vialou, V., Covington, H. E. 3rd, Dumitriu, D., Feng, J., Warren, B. L., Maze, I., Dietz, D. M., Watts, E.
L., Iniguez, S. D., Koo, J. W., Mouzon, E., Renthal, W., Hollis, F., Wang, H., Noonan, M. A., Ren, Y., Eisch, A J., Bolanos, C. A., Kabbaj, M., Xiao, G., Neve, R. L., Hurd, Y. L., Oosting, R. S., Fan, G., Morrison, J. H., and Nestler, E. J. (2010). Dnmt3a regulates emotional behavior and spine plasticity in the nucleus accumbens. Nat. Neurosci. 13, 1137-1143.

Lee, S. J., Matsuura, Y., Liu, S. M., and Stewart, M. (2005). Structural basis for nuclear import complex dissociation by RanGTP. Nature 435, 693-696.

Levenson, J. M., and Sweatt, J. D. (2005). Epigenetic mechanisms in memory formation. Nat. Rev. Neurosci. 6, 108-118.

Levine, A. A., Guan, Z., Barco, A., Xu, S., Kandel, E. R., and Schwartz, J. H (2005). CREB-binding protein controls response to cocaine by acetylating histones at the fosB promoter in the mouse striatum. Proc. Natl. Acad. Sci. U.S.A. 102, 19186-19191.

Li, J., Guo, Y., Schroeder, F. A., Youngs, R. M., Schmidt, T. W., Ferris, C., Konradi, C., and Akbarian, S. (2004). Dopamine D2-like antagonists induce chromatin remodeling in striatal neurons through cyclic AMP-protein kinase A and NMDA receptor signaling. J. Neurochem. 90, 1117-1131.

Lidke, D. S., Huang, F., Post, J. N., Rieger, B., Wilsbacher, J., Thomas, J. L., Pouyssegur, J., Jovin, T. M., and Lenormand, P. (2010). ERK nuclear translocation is dimerizationindependent but controlled by the rate of phosphorylation. J. Biol. Chem. 285, 3092-3102.

Lischka, P., Rosorius, O., Trommer, E., and Stamminger, T. (2001). A novel transferable nuclear export signal mediates CRM1-independent nucleocytoplasmic shuttling of the human cytomegalovirus transactivator protein pUL69. EMBO J. 20, 7271-7283.

Martin, K. C., Michael, D., Rose, J. C., Barad, M., Casadio, A. Zhu, H. X., and Kandel, E. R. (1997). MAP kinase translocates into the nucleus of the presynaptic cell and is required for long-term facilitation in Aplysia. Neuron 18, 899-912.

Matamales, M., Bertran-Gonzalez, J. Salomon, L., Degos, B., Deniau, J. M. Valjent, E., Herve, D., and Girault, J. A. (2009). Striatal mediumsized spiny neurons: identification by nuclear staining and study of neuronal subpopulations in BAC transgenic mice. PLoS ONE 4, e4770. doi: 10.1371/journal.pone. 0004770 
Matsushita, M., Tomizawa, K., Moriwaki, A., Li, S. T., Terada, H., and Matsui, H. (2001). A high-efficiency protein transduction system demonstrating the role of PKA in longlasting long-term potentiation. J. Neurosci. 21, 6000-6007.

Maze, I., Covington, H. E., 3rd, Dietz, D. M., LaPlant, Q., Renthal, W., Russo, S. J., Mechanic, M., Mouzon, E., Neve, R. L., Haggarty, S. J., Ren, Y., Sampath, S. C., Hurd, Y. L., Greengard, P., Tarakhovsky, A., Schaefer, A., and Nestler, E. J. (2010). Essential role of the histone methyltransferase G9a in cocaine-induced plasticity. Science 327, 213-216.

Maze, I., Feng, J., Wilkinson, M. B., Sun, H., Shen, L., and Nestler, E. J. (2011). Cocaine dynamically regulates heterochromatin and repetitive element unsilencing in nucleus accumbens. Proc. Natl. Acad. Sci. U.S.A. 108, 3035-3040.

Meffert, M. K., Chang, J. M., Wiltgen, B. J., Fanselow, M. S., and Baltimore, D. (2003). NF-kappa B functions in synaptic signaling and behavior. Nat. Neurosci. 6, 1072-1078.

Meinkoth, J. L., Ji, Y., Taylor, S. S., and Feramisco, J. R. (1990). Dynamics of the distribution of cyclic AMPdependent protein kinase in living cells. Proc. Natl. Acad. Sci. U.S.A. 87, 9595-9599.

Miyamoto, E., Kuo, J. F., and Greengard, P. (1968). Adenosine $3^{\prime}, 5^{\prime}$ monophosphate-dependent protein kinase from brain. Science 165, 63-65.

Moorhead, G. B. G., Trinkle-Mulcahy, L., and Ulke-Lemée, A. (2007). Emerging roles of nuclear protein phosphatases. Nat. Rev. Mol. Cell Biol. 7, 235-244.

Mosammaparast, N., and Pemberton, L. F. (2004). Karyopherins: from nuclear-transport mediators to nuclear-function regulators. Trends Cell Biol. 14, 547-556.

Nardozzi, J. D., Lott, K., and Cingolani, G. (2010). Phosphorylation meets nuclear import: a review. Cell Commun. Signal 8, 32.

Nestler, E. J. (2008). Review. Transcriptional mechanisms of addiction: role of DeltaFosB. Philos. Trans. R. Soc. Lond., B, Biol. Sci. 363, 3245-3255.

Nicholas, A. P., Lubin, F. D., Hallett, P. J., Vattem, P., Ravenscroft, P., Bezard, E., Zhou, S., Fox, S. H., Brotchie, J. M., Sweatt, J. D., and Standaert, D. G. (2008). Striatal histone modifications in models of levodopainduced dyskinesia. J. Neurochem. 106, 486-494.

Nicola, S. M., Surmeier, J., and Malenka, R. C. (2000). Dopaminergic modulation of neuronal excitability in the striatum and nucleus accumbens. Annu. Rev. Neurosci. 23, 185-215.

Ouimet, C. C., da Cruz e Silva, E. F., and Greengard, P. (1995). The alpha and gamma 1 isoforms of protein phosphatase 1 are highly and specifically concentrated in dendritic spines. Proc. Natl. Acad. Sci. U.S.A. 92, 3396-3400.

Ouimet, C. C., Miller, P. E., Hemmings, H. C. Jr., Walaas, S. I., and Greengard, P. (1984). DARPP32, a dopamine- and adenosine $3^{\prime}: 5^{\prime}$-monophosphate- regulated phosphoprotein enriched in dopamine-innervated brain regions. III Immunocytochemical localization. J. Neurosci. 4, 111-124.

Paolillo, M., Feliciello, A., Porcellini, A., Garbi, C., Bifulco, M., Schinelli, S., Ventra, C., Stabile, E., Ricciardelli, G., Schettini, G., and Avvedimento, E. V. (1999). The type and the localization of cAMPdependent protein kinase regulate transmission of cAMP signals to the nucleus in cortical and cerebellar granule cells. J. Biol. Chem. 274, 6546-6552.

Pascoli, V., Besnard, A., Herve, D., Pages, C., Heck, N., Girault, J. A., Caboche, J., and Vanhoutte, P. (2011). Cyclic adenosine monophosphate- independent tyrosine phosphorylation of NR2B mediates cocaine- induced extracellular signal- regulated kinase activation. Biol. Psychiatry 69, 218-227.

Patel, S. S., Belmont, B. J., Sante, J. M., and Rexach, M. F. (2007). Natively unfolded nucleoporins gate protein diffusion across the nuclear pore complex. Cell 129, 83-96.

Patterson, S. L., Pittenger, C., Morozov, A., Martin, K. C., Scanlin, H., Drake, C., and Kandel, E. R. (2001). Some forms of cAMP-mediated long-lasting potentiation are associated with release of BDNF and nuclear translocation of phospho-MAP kinase. Neuron 32, 123-140.

Pemberton, L. F., and Paschal, B. M. (2005). Mechanisms of receptormediated nuclear import and nuclear export. Traffic 6, 187-198.

Petrij, F., Giles, R. H., Dauwerse, H. G., Saris, J. J., Hennekam, R. C., Masuno, M., Tommerup, N., van Ommen, G. J., Goodman, R. H., Peters, D. J., and Breuning, M. H. (1995). Rubinstein-Taybi syndrome caused by mutations in the transcriptional co-activator CBP. Nature 376, 348-351.

Poon, I. K., and Jans, D. A. (2005). Regulation of nuclear transport: central role in development and transformation? Traffic 6, 173-186.
Ptashne, M. (2007). On the use of the word 'epigenetic'. Curr. Biol. 17, R233-6.

Ramon y Cajal, S. (1899). Textura del Sistema Nervioso del Hombre $y$ de los Vertebrados. French translation, Maloine, Paris, 1955, I, 195-201.

Renthal, W., Kumar, A., Xiao, G., Wilkinson, M., Covington, H. E., 3rd, Maze, I., Sikder, D., Robison, A. J., LaPlant, Q., Dietz, D. M., Russo, S. J., Vialou, V., Chakravarty, S., Kodadek, T. J., Stack, A., Kabbaj, M., and Nestler, E. J. (2009). Genome-wide analysis of chromatin regulation by cocaine reveals a role for sirtuins. Neuron 62 , 335-348.

Riccio, A. (2010). Dynamic epigenetic regulation in neurons: enzymes, stimuli and signaling pathways. Nat. Neurosci. 13, 1330-1337.

Santini, E., Alcacer, C., Cacciatore, S., Heiman, M., Herve, D., Greengard, P., Girault, J. A., Valjent, E., and Fisone, G. (2009). L-DOPA activates ERK signaling and phosphorylates histone $\mathrm{H} 3$ in the striatonigral medium spiny neurons of hemiparkinsonian mice. J. Neurochem. 108, 621-633.

Santini, E., Valjent, E., Usiello, A., Carta, M., Borgkvist, A., Girault, J. A., Herve, D., Greengard, P., and Fisone, G. (2007). Critical involvement of cAMP/DARPP-32 and extracellular signal-regulated protein kinase signaling in L-DOPA-induced dyskinesia. J. Neurosci. 27, 6995-7005.

Sastri, M., Barraclough, D. M. Carmichael, P. T., and Taylor, S. S. (2005). A-kinase-interacting protein localizes protein kinase $\mathrm{A}$ in the nucleus. Proc. Natl. Acad. Sci. U S A 102, 349-354.

Sgambato, V., Pagès, C., Rogard, M., Besson, M. J., and Caboche, J. (1998). Extracellular signalregulated kinase (ERK) controls immediate early gene induction on corticostriatal stimulation. J. Neurosci. 18, 8814-8825.

Shaywitz, A. J., and Greenberg, M. E. (1999). CREB: a stimulus-induced transcription factor activated by a diverse array of extracellular signals. Annu. Rev. Biochem. 68 821-861.

Shilatifard, A. (2006). Chromatin modifications by methylation and ubiquitination: implications in the regulation of gene expression. Annu. Rev. Biochem. 75, 243-269.

Stipanovich, A., Valjent, E., Matamales, M., Nishi, A., Ahn, J. H., Maroteaux, M., Bertran-Gonzalez, J., BramiCherrier, K., Enslen, H., Corbille, A. G., Filhol, O., Nairn, A. C., Greengard, P., Herve, D., and Girault, J.
A. (2008). A phosphatase cascade by which rewarding stimuli control nucleosomal response. Nature 453, 879-884.

Svenningsson, P., Nishi, A., Fisone, G., Girault, J. A., Nairn, A. C., and Greengard, P. (2004). DARPP-32: an integrator of neurotransmission. Annu. Rev. Pharmacol. Toxicol. 44, 269-296.

Taylor, S. S., Buechler, J. A., and Yonemoto, W. (1990). cAMPdependent protein kinase: framework for a diverse family of regulatory enzymes. Annu. Rev. Biochem. 59, 971-1005.

Taylor, S. S., Kim, C., Cheng, C. Y., Brown, S. H., Wu, J., and Kannan, N. (2008). Signaling through cAMP and cAMP-dependent protein kinase: diverse strategies for drug design. Biochim. Biophys. Acta 1784, 16-26.

Tepper, J. M., and Bolam, J. P. (2004). Functional diversity and specificity of neostriatal interneurons. Curr. Opin. Neurobiol. 14, 685-692.

Terry, L. J., Shows, E. B., and Wente, S. R. (2007). Crossing the nuclear envelope: hierarchical regulation of nucleocytoplasmic transport. Science 318, 1412-1416.

Thomas, G. M., and Huganir, R. L. (2004). MAPK cascade signalling and synaptic plasticity. Nat. Rev. Neurosci. 5, 173-183.

Thompson, K. R., Otis, K. O., Chen, D. Y., Zhao, Y., O'Dell, T. J., and Martin, K. C. (2004). Synapse to nucleus signaling during longterm synaptic plasticity; a role for the classical active nuclear import pathway. Neuron 44, 997-1009.

Toki, S., Kawasaki, H., Tashiro, N., Housman, D. E., and Graybiel, A. M. (2001). Guanine nucleotide exchange factors CalDAG-GEFI and CalDAG-GEFII are colocalized in striatal projection neurons. J. Comp. Neurol. 437, 398-407.

Trifilieff, P., Lavaur, J., Pascoli, V., Kappes, V., Brami-Cherrier, K., Pages, C., Micheau, J., Caboche, J., and Vanhoutte, P. (2009). Endocytosis controls glutamateinduced nuclear accumulation of ERK. Mol. Cell. Neurosci. 41, 325-336.

Tsankova, N., Renthal, W., Kumar, A., and Nestler, E. J. (2007). Epigenetic regulation in psychiatric disorders. Nat. Rev. Neurosci. 8, 355-367.

Valjent, E., Bertran-Gonzalez, J., Herve, D., Fisone, G., and Girault, J. A. (2009). Looking BAC at striatal signaling: cell-specific analysis in new transgenic mice. Trends Neurosci. 32, 538-547. 
Valjent, E., Corvol, J. C., Pages, C., Besson, M. J., Maldonado, R., and Caboche, J. (2000). Involvement of the extracellular signalregulated kinase cascade for cocainerewarding properties. J. Neurosci. 20, 8701-8709.

Valjent, E., Pages, C., Herve, D., Girault, J. A., and Caboche, J. (2004). Addictive and non-addictive drugs induce distinct and specific patterns of ERK activation in mouse brain. Eur. J. Neurosci. 19, 1826-1836.

Valjent, E., Pages, C., Rogard, M., Besson, M. J., Maldonado, R., and Caboche, J. (2001). Delta 9-tetrahydrocannabinol-induced MAPK/ERK and Elk-1 activation in vivo depends on dopaminergic transmission. Eur. J. Neurosci. 14 342-352.

Valjent, E., Pascoli, V., Svenningsson, P., Paul, S., Enslen, H., Corvol, J. C., Stipanovich, A., Caboche, J., Lombroso, P. J., Nairn, A. C., Greengard, P., Herve, D., and Girault, J. A. (2005). Regulation of a protein phosphatase cascade allows convergent dopamine and glutamate signals to activate ERK in the striatum. Proc. Natl. Acad. Sci. U.S.A. 102, 491-496.

Vanhoutte, P., Barnier, J. V., Guibert, B., Pagès, C., Besson, M. J., Hipskind, R. A., and Caboche, J. (1999). Glutamate induces phosphorylation of Elk-1 and CREB, along with c-fos activation, via an extracellular signal-regulated kinase-dependent pathway in brain slices. Mol. Cell. Biol. 19, 136-146.

Walaas, S. I., Aswad, D. W., and Greengard, P. (1983). A dopamineand cyclic AMP-regulated phosphoprotein enriched in dopamineinnervated brain regions. Nature 301, 69-71.

Wang, B., Li, Z., Xu, L., Goggi, J., Yu, Y., and Zhou, J. (2004). Molecular cloning and characterization of rat karyopherin alpha 1 gene: structure and expression. Gene 331, 149-157.

Wang, J. Q., Fibuch, E. E., and Mao, L. (2007). Regulation of mitogenactivated protein kinases by glutamate receptors. J. Neurochem. 100, $1-11$.
Wittmann, M., Queisser, G., Eder, A. Wiegert, J. S., Bengtson, C. P., Hellwig, A., Wittum, G., and Bading, H. (2009). Synaptic activity induces dramatic changes in the geometry of the cell nucleus: interplay between nuclear structure, histone H3 phosphorylation, and nuclear calcium signaling. J. Neurosci. 29, 14687-14700.

Wong, W., and Scott, J. D. (2004). AKAP signalling complexes: focal points in space and time. Nat. Rev. Mol. Cell Biol. 5, 959-970.

$\mathrm{Xu}$, D., Farmer, A., and Chook, Y. M. (2010). Recognition of nuclear targeting signals by Karyopherinbeta proteins. Curr. Opin. Struct. Biol. 20, 782-790.

Yoshida, M., and Precht, W. (1971). Monosynaptic inhibition of neurons of the substantia nigra by caudato-nigral fibers. Brain Res. 32 , 225-228.

Zhang, L., Lou, D., Jiao, H., Zhang, D., Wang, X., Xia, Y., Zhang, J., and $\mathrm{Xu}$, M. (2004). Cocaine-induced intracellular signaling and gene expression are oppositely regulated by the dopamine D1 and D3 receptors. J. Neurosci. 24, 3344-3354.

Conflict of Interest Statement: The authors declare that the research was conducted in the absence of any commercial or financial relationships that could be construed as a potential conflict of interest.

Received: 29 May 2011; paper pending published: 10 June 2011; accepted: 13 June 2011; published online: 06 July 2011.

Citation: Matamales $M$ and Girault J-A (2011) Signaling from the cytoplasm to the nucleus in striatal medium-sized spiny neurons. Front. Neuroanat. 5:37. doi: 10.3389/fnana.2011.00037

Copyright (c) 2011 Matamales and Girault. This is an open-access article subject to a non-exclusive license between the authors and Frontiers Media SA, which permits use, distribution and reproduction in other forums, provided the original authors and source are credited and other Frontiers conditions are complied with. 